\title{
Characterization of Yersinia Species by Analysis of Whole- Cell Fatty Acids
}

\author{
ERIK JANTZEN AND JØRGEN LASSEN \\ National Institute of Public Health, Oslo, Norway
}

The cellular fatty acid composition of Yersinia enterocolitica (50 strains, including all recognized biovars), Y. pseudotuberculosis (7 strains), and Y.pestis (1 strain) was determined by gas-liquid chromatography. All species showed a generally similar pattern characterized by relatively large amounts of 3-OH-14:0, 16:1, 16:0, 17:0-cyclo, and 18:1. The heterogeneity of $Y$. enterocolitica as revealed by biochemical reactions and by deoxyribonucleic acid-deoxyribonucleic acid hybridization was not found to be reflected in the fatty acid composition. Only small interspecies differences were detected. Y. enterocolitica differed slightly from Y. pseudotuberculosis by its higher concentrations of 12:0, 16:0, and 17:0 and its lower content of 14:0. Y. pestis was characterized by its high content of 18: 1, low content of 15:0, and absence of 13:0. A reference group of five Salmonella typhi strains showed a fatty acid pattern grossly comparable to that of yersiniae, but the following differences were noted: the presence in $S$. typhi of an additional compound, 2-OH-14:0, relatively high concentrations of 14:0 and 16:0, and low amounts of 15:0, 16:0, and 17:0. Thus, the genus Yersinia appears relatively homogeneous with respect to fatty acid composition, and the present results do not support per se a splitting of $Y$. enterocolitica into additional species. Furthermore, the high degree of similarity of the fatty acid patterns of yersiniae and $S$. typhi agrees well with the present placement of Yersinia in the family Enterobacteriaceae.

The genus Yersinia presently is placed in the family Enterobacteriaceae and consists of three species: Yersinia enterocolitica, Y. pseudotuberculosis, and $Y$.pestis (6). Due to the clinical significance of these three species, their taxonomy has been extensively studied $(2,3,13-15$, $19,21,24)$, but some points are still unclear.

Deoxyribonucleic acid (DNA)-DNA hybridization experiments $(3,19)$ and numerical analysis of biochemical tests (13) define Y. pseudotuberculosis and apparently also $Y$. pestis as homogeneous groups compatible with the concept of single species. $Y$. enterocolitica is more heterogeneous, and several subgroups have been proposed mainly on the basis of biochemical characteristics $(3,14,21,24)$. A splitting of this group into two or more species has also been suggested $(3,14)$.

Regarding interspecies relatedness, the literature is conflicting. On the basis of DNA-DNA hybridization, the taxonomic position of $Y$. enterocolitica seems to be relatively distant from both Y.pseudotuberculosis and Y.pestis $(3,19)$. Actually, the genetic affinities between $Y$. enterocolitica and $Y$. pseudotuberculosis strains were found to be so weak that Moore and Brubaker (19) questioned the inclusion of $Y$. enterocolitica in the genus Yersinia. The DNA homology between Y.pseudotuberculosis and $Y$. pestis is apparently at a higher level $(3,19)$. On the other hand, comparative analyses of protein antigens indicated a strong relationship between Y. enterocolitica and Y.pestis (2), and all three species contain "enterobacterial common antigen" $(17,18)$.

Fatty acid patterns of bacterial whole cells or extractable lipids have proved to be a useful aid in taxonomic evaluations $(1,8,12,16,22)$. In this study we wanted to analyze representative strains of Yersinia for fatty acid composition. The main objectives were to find out to what extent fatty acid patterns could be used to differentiate Y. enterocolitica, Y. pseudotuberculosis, and $Y$. pestis and to confirm the reported heterogeneity of $Y$. enterocolitica. Five strains of Salmonella typhi, which served mainly as representatives of an unequivocal Enterobacteriaceae species, were also examined.

\section{MATERIALS AND METHODS}

Bacterial strains. Fifty-eight strains of Yersinia and five of Salmonella typhi were analyzed (Table 1). H. H. Mollaret, Institut Pasteur, Paris, kindly provided 31 Y. enterocolitica strains, whereas the 7 Y.pseudotuberculosis strains were a gift from S. Winblad, Malmö, Sweden. One S. typhi strain (NCTC 57) and 


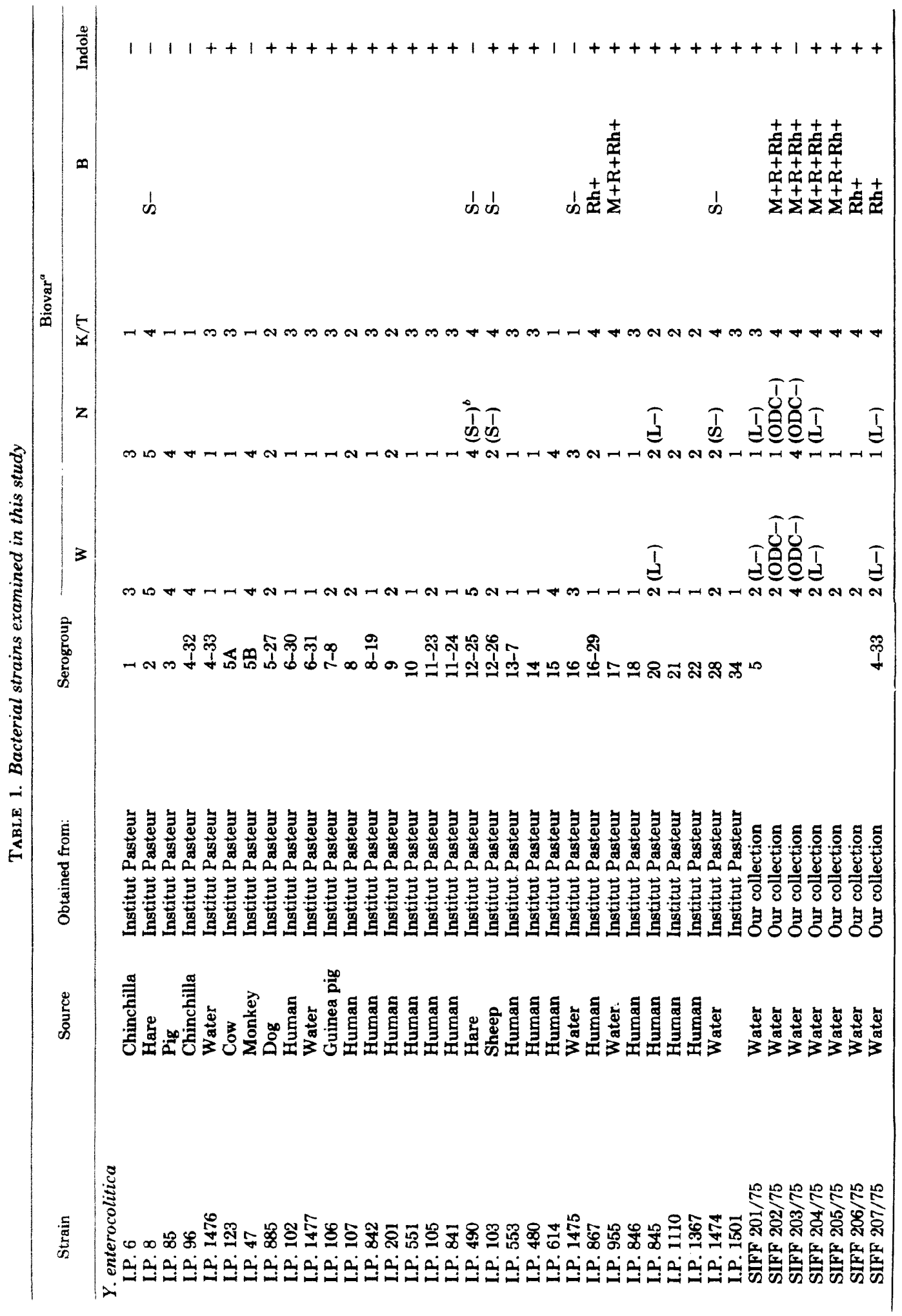




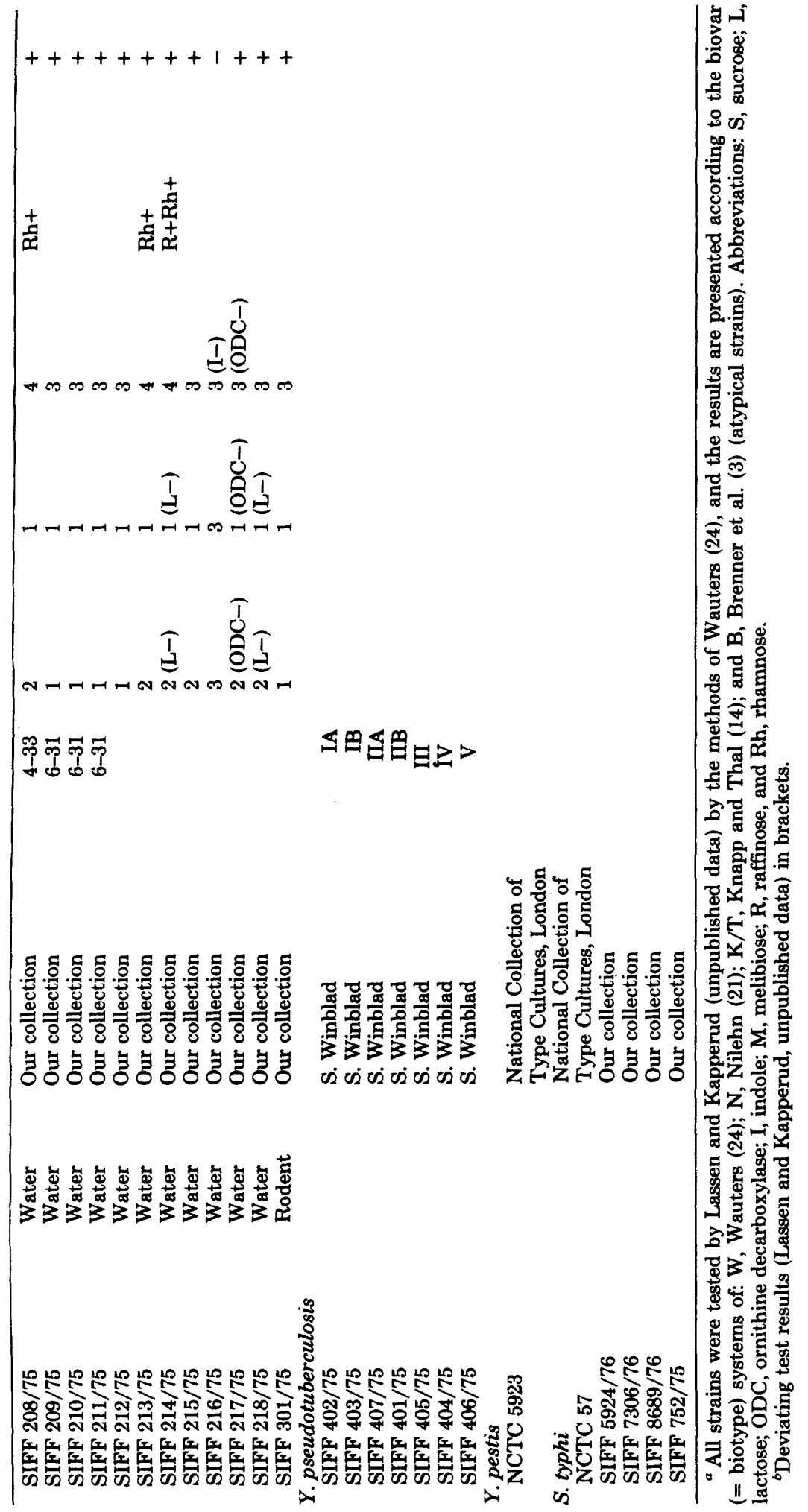


the single strain of $Y$. pestis were obtained from the National Collection of Type Cultures, London. The remaining strains were from our own collection, and their biochemical properties are indicated in Table 1 (15; Lassen and Kapperud, unpublished data).

Medium. All strains were maintained and cultivated on blood agar base (Oxoid) supplemented with 5\% citrated horse serum, $\mathrm{pH}$ 7.2. A single batch of medium was used for cultivation. Incubations were performed for $24 \mathrm{~h}$ at $37^{\circ} \mathrm{C}$. The bacteria were carefully removed from the agar surface by the aid of a phosphate buffer $(0.5 \mathrm{M}, \mathrm{pH} 7.2)$ and were then centrifuged and washed twice by distilled water before freeze drying. The medium composition and growth conditions were carefully standardized.

Chemicals. Solvents of analytical grade were distilled before use. The standards of fatty acid methyl esters were obtained from Applied Science Laboratories Inc., State College, $\mathrm{Pa}$.

Chemical procedures and gas chromatography. Dried bacterial cells ( 1 to $10 \mathrm{mg}$ ) were methanolyzed by $2 \mathrm{~N} \mathrm{HCl}$ in methanol $(10,11)$. Since the strains of the present study contain cyclopropane fatty acids, which largely are destroyed by acidic methanolysis, a saponification-reesterification procedure was also used (12).

Fatty acid methyl esters were analyzed on a Hewlett-Packard 5750 gas chromatograph, as described previously $(10,11)$. Two columns, packed with either $10 \%$ SE-30 or EGA on Gas Chrom Q (100 to 120 mesh), were used. In the later stage of the study, the EGA column was replaced by a $10 \%$ CP -10 on a Gas Chrom $\mathrm{Q}$ column (Applied Science Laboratories Inc.).

Gas chromatographic peaks were primarily characterized by comparing retention times of unknown peaks to those of fatty acid methyl ester standards. The identities of the cyclopropane fatty acids were confirmed by the reduction procedure of Brian and Gardner (4). For identification, hydroxy fatty acid methyl esters were separated from the other esters by chromatography on silica (20) and were gas chromatographed separately. Generally, the fatty acid identities were confirmed by mass spectrometry, in which a Hewlett-Packard 5992A gas chromatograph-mass spectrometer-computer system equipped with a glass column (200 by $0.2 \mathrm{~cm}$ ) packed with $1 \%$ SE-30 on Gas Chrom $Q$ was used. The quadrupole mass spectrometer was automatically calibrated (AUTOTUNE program) with a perfluorotetrabutylamine (PFTBA) reference compound to a fixed set of mass spectral conditions; the intensity ratio of the peaks at $m / e 69,219$, and 502 was adjusted to $100: 35: 2$. The ionization conditions used were $70 \mathrm{eV}$ at $170^{\circ} \mathrm{C}$.

Numerical methods. The percent fatty acid composition of each bacterial strain was calculated on the basis of the integrator (Hewlett-Packard 3370B) printouts of two chromatograms. The primary data (percent peak area) were obtained after acidic methanolysis and chromatography on the SE-30 column (see above). These values were then adjusted by the corresponding peak area data obtained by the second chromatographic run, e.g., that of the alkaline methanolysates on the EGA or CP-10 column.

The fatty acid compositions of the 63 strains are not presented. Instead, these values were reduced to mean values, ranges, and standard errors for each species and certain biovars of $Y$. enterocolitica (Table 2). The evaluation of the taxonomic distances between pairs of groups and species (Table 3) was based on the differences between pairs of corresponding fatty acid mean values and their associated standard errors. Two significance levels of differences were defined for two $(P \sim 0.07)$ and three times $(P \sim 0.02)$ the levels of standard error, respectively.

A numerical expression of fatty acid-based relatedness was achieved by use of the following similarity index:

$$
\frac{1}{n} \sum_{i=1}^{n} \sqrt{\frac{\left(\bar{x}_{1 i}-\bar{x}_{2 i}\right)^{2}}{\left(\sigma_{1 i}-\sigma_{2 i}\right)^{2}}}
$$

$\overline{\boldsymbol{x}}_{1 i}$ and $\overline{\mathbf{x}}_{2 i}$ express the mean fatty acid concentrations of two bacterial groups to be compared, respectively; $\sigma_{1 i}$ and $\sigma_{2 i}$ denote the associated standard deviations; and $n$ is the number of fatty acids, i.e., 16 .

\section{RESULTS}

As shown in Table 2, all Yersinia strains exhibit a similar fatty acid pattern characterized by high levels of the acids 3-OH-14:0, 16:1, 16:0, 17:0-cyclo, and 18:1 (see Table 2 for nomenclature and abbreviations). Also found in almost all strains but in lower and more variable concentrations were 12:0,3-OH-13:0, 14:0, 15:0, 17:0, and 19:0-cyclo fatty acids.

All strains contained hydroxy- and cyclopropane fatty acids in addition to the straight-chain saturated and unsaturated acids. These two classes of fatty acids have been shown to be interesting chemotaxonomic markers of bacteria $(16,22)$. However, cyclopropane fatty acids are degraded by methanolic hydrochloride and require alkaline conditions for methyl ester formation $(4,23)$. Optimal yield of hydroxy fatty acids, on the other hand, is apparently dependent on an acidic catalyzed methanolysis (12). Accordingly, all strains were methanolyzed under both acidic and alkaline conditions.

The biosynthesis of cyclopropane fatty acids tends to be especially dependent on growth conditions and the stage of the life cycle of the cells (7); this is probably the reason for the relatively high variation of 17:0-cyclo fatty acid, as well as its precursor 16:1 (7), observed for all species (Table 2). The quantitative value of these two acids is therefore questionable in taxonomic evaluations. On the other hand, their sum showed a more normal variation, with a standard error below 3\% (Table 2).

The presence of hydroxy fatty acids appeared to be of particular taxonomic interest (see below). Their occurrence was, therefore, determined by separate analysis, which included preparative thin-layer chromatography (20) and subsequent gas chromatography-mass spec- 
TABLE 2. Composition of fatty acids from Yersinia species and S. typhi

\begin{tabular}{|c|c|c|c|c|c|}
\hline \multirow[b]{2}{*}{ Fatty acid ${ }^{a}$} & \multicolumn{2}{|c|}{ Y. enterocolitica } & \multirow{2}{*}{$\begin{array}{l}\text { Y. pseudo- } \\
\text { tuberculosis } \\
\text { (7 strains) }\end{array}$} & \multirow[b]{2}{*}{$\begin{array}{l}Y . \text { pestis } \\
\text { (1 strain) }\end{array}$} & \multirow[b]{2}{*}{$\begin{array}{l}\text { S. typhi } \\
\text { (5 strains) }\end{array}$} \\
\hline & $\begin{array}{c}\text { Biovars } \\
1 \text { and } 2 \\
\text { (39 strains) } \\
\end{array}$ & $\begin{array}{c}\text { Biovars } \\
3,4, \text { and } 5 \\
\text { (11 strains) } \\
\end{array}$ & & & \\
\hline $12: 0$ & $\begin{array}{c}2.3^{b} \\
1.5-3.3^{c} \\
0.08^{d}\end{array}$ & $\begin{array}{c}2.2 \\
1.3-3.3 \\
0.23\end{array}$ & $\begin{array}{c}1.2 \\
0.6-2.6 \\
0.27\end{array}$ & 1.0 & $\begin{array}{c}0.9 \\
0.1-1.6 \\
0.25\end{array}$ \\
\hline $13: 0$ & $\begin{array}{c}0.5 \\
0.1-1.0 \\
0.04\end{array}$ & $\begin{array}{c}0.4 \\
0.1-0.8 \\
0.08\end{array}$ & $\begin{array}{c}0.3 \\
0.1-0.5 \\
0.06\end{array}$ & $-^{e}$ & $\begin{array}{c}0.2 \\
0.1-0.4 \\
0.09\end{array}$ \\
\hline 3-OH-13:0 & $\begin{array}{c}1.1 \\
0.2-2.1 \\
0.06\end{array}$ & $\begin{array}{c}1.4 \\
0.3-2.6 \\
0.19\end{array}$ & $\begin{array}{c}1.7 \\
1.0-2.0 \\
0.14\end{array}$ & 0.5 & $\begin{array}{l}0.1 \\
0-0.2 \\
0.04\end{array}$ \\
\hline $14: 0$ & $\begin{array}{c}0.7 \\
0.4-1.7 \\
0.04\end{array}$ & $\begin{array}{c}1.1 \\
0.5-1.8 \\
0.15\end{array}$ & $\begin{array}{c}0.4 \\
0.2-0.4 \\
0.03\end{array}$ & 0.4 & $\begin{array}{c}4.5 \\
3.9-5.0 \\
0.20\end{array}$ \\
\hline 2-OH-14:0 & - & - & - & - & $\begin{array}{c}0.4 \\
0.2-0.5 \\
0.17\end{array}$ \\
\hline 3-OH-14:0 & $\begin{array}{c}9.7 \\
8.0-12.2 \\
0.13\end{array}$ & $\begin{array}{c}10.5 \\
9.2-11.9 \\
0.33\end{array}$ & $\begin{array}{c}9.5 \\
9.2-10.3 \\
0.22\end{array}$ & 10.1 & $\begin{array}{c}11.4 \\
10.9-12.6 \\
0.32\end{array}$ \\
\hline 15:0 & $\begin{array}{c}5.7 \\
1.4-9.3 \\
0.32\end{array}$ & $\begin{array}{c}6.2 \\
1.4-11.9 \\
1.02\end{array}$ & $\begin{array}{c}7.0 \\
5.0-8.0 \\
0.44\end{array}$ & 1.7 & $\begin{array}{c}1.4 \\
0.7-2.7 \\
0.34\end{array}$ \\
\hline $16: 1$ & $\begin{array}{c}22.2 \\
14.3-29.1 \\
0.59\end{array}$ & $\begin{array}{c}25.6 \\
20.8-28.2 \\
0.95\end{array}$ & $\begin{array}{c}23.4 \\
10.6-28.3 \\
2.36\end{array}$ & 25.5 & $\begin{array}{c}8.5 \\
3.8-17.8 \\
2.90\end{array}$ \\
\hline $16: 0$ & $\begin{array}{c}20.5 \\
15.6-30.6 \\
0.48\end{array}$ & $\begin{array}{c}20.6 \\
13.5-29.2 \\
1.58\end{array}$ & $\begin{array}{c}16.5 \\
14.7-19.8 \\
0.64\end{array}$ & 21.9 & $\begin{array}{c}34.9 \\
31.9-36.8 \\
1.05\end{array}$ \\
\hline 17:0-cyclo & $\begin{array}{c}16.2 \\
9.1-22.7 \\
0.58\end{array}$ & $\begin{array}{c}11.8 \\
4.9-16.2 \\
1.06\end{array}$ & $\begin{array}{c}17.4 \\
12.2-27.4 \\
2.03\end{array}$ & 13.9 & $\begin{array}{c}18.5 \\
8.7-24.0 \\
3.41\end{array}$ \\
\hline $17: 0$ & $\begin{array}{c}3.8 \\
0.7-5.4 \\
0.17\end{array}$ & $\begin{array}{c}4.2 \\
0.7-7.0 \\
0.63\end{array}$ & $\begin{array}{c}6.9 \\
4.4-8.1 \\
0.51\end{array}$ & 2.1 & $\begin{array}{c}0.8 \\
0.2-1.7 \\
0.25\end{array}$ \\
\hline $18: 2$ & $\begin{array}{c}5.3 \\
2.8-7.4 \\
0.19\end{array}$ & $\begin{array}{c}4.0 \\
2.6-5.6 \\
0.28\end{array}$ & $\begin{array}{c}4.6 \\
3.5-9.2 \\
0.85\end{array}$ & 2.1 & $\begin{array}{c}5.5 \\
1.9-7.8 \\
1.43\end{array}$ \\
\hline 18:1 & $\begin{array}{c}11.3 \\
8.8-13.6 \\
0.20\end{array}$ & $\begin{array}{l}11.4 \\
9.6-12.5 \\
0.34\end{array}$ & $\begin{array}{c}9.8 \\
5.3-12.4 \\
0.90\end{array}$ & 20.6 & $\begin{array}{l}12.8 \\
8.0-19.4 \\
2.51\end{array}$ \\
\hline 18:0 & $\begin{array}{c}0.6 \\
0.1-1.3 \\
0.05\end{array}$ & $\begin{array}{c}0.5 \\
0.1-1.0 \\
0.1\end{array}$ & $\begin{array}{c}0.4 \\
0.1-0.7 \\
0.11\end{array}$ & 1.4 & $\begin{array}{c}0.9 \\
0.1-1.7 \\
0.31\end{array}$ \\
\hline 19:0-cyclo & $\begin{array}{l}0.2 \\
0-0.6 \\
\end{array}$ & $\begin{array}{l}0.1 \\
0-0.3 \\
\end{array}$ & $\begin{array}{l}0.6 \\
0-2.9 \\
\end{array}$ & 0.3 & $\begin{array}{c}0.2 \\
0.1-0.2 \\
\end{array}$ \\
\hline
\end{tabular}


TABLE 2-continued

\begin{tabular}{|c|c|c|c|c|c|}
\hline \multirow[b]{2}{*}{ Fatty acid ${ }^{a}$} & \multicolumn{2}{|c|}{ Y. enterocolitica } & \multirow[b]{2}{*}{$\begin{array}{l}Y . \text { pseudo- } \\
\text { tuberculosis } \\
\text { (7 strains) }\end{array}$} & \multirow[b]{2}{*}{$\begin{array}{l}Y . \text { pestis } \\
\text { (1 strain) }\end{array}$} & \multirow[b]{2}{*}{$\begin{array}{c}\text { S. typhi } \\
\text { (5 strains) }\end{array}$} \\
\hline & $\begin{array}{c}\text { Biovars } \\
1 \text { and } 2 \\
(39 \text { strains) }\end{array}$ & $\begin{array}{c}\text { Biovars } \\
3,4 \text {, and } 5 \\
\text { (11 strains) }\end{array}$ & & & \\
\hline & 0.05 & 0.04 & 0.42 & & 0.04 \\
\hline $\begin{array}{l}16: 1+ \\
17: 0-\text {-yclo }\end{array}$ & $\begin{array}{c}38.4 \\
33.5-40.8 \\
0.22\end{array}$ & $\begin{array}{c}37.4 \\
35.4-39.4 \\
0.43\end{array}$ & $\begin{array}{c}40.6 \\
38.0-42.6 \\
0.72\end{array}$ & 39.4 & $\begin{array}{c}27.0 \\
24.7-28.3 \\
0.66\end{array}$ \\
\hline
\end{tabular}

"The figure in front of the colon indicates the number of carbon atoms in the chain, and the figure after the colon indicates the number of double bonds; $2-\mathrm{OH}$ and $3-\mathrm{OH}$ indicate hydroxyl groups and their positions. The term "cyclo" refers to a cyclopropane ring in the chain.

${ }^{b}$ Mean value of the relative amount (percentage of total) of fatty acids.

"Range among strains.

${ }^{d}$ Standard error.

- Below the limit of detection

trometry. These analyses were performed for two strains of each species (one of $Y$. pestis). In general, the results confirmed the identification obtained by gas-liquid chromatography (GLC) retention times on unfractionated whole-cell methanolysates.

All biovars included in the study were members of $Y$. enterocolitica (Table 1). None of the biochemical distinctions of the biovars was clearly reflected in the fatty acid patterns of the strains. Also, when indole-positive strains (biovars 1 and 2, according to Wauters) were compared with indole-negative strains (biovars 3,4 , and 5), almost negligible differences were noted (Table 3). Furthermore, no clear correlation between source of origin (Table 1) and fatty acid composition could be seen.

The differences between $Y$. enterocolitica and Y. pseudotuberculosis are also small (Tables 2 and 3). Y. enterocolitica contained slightly higher concentrations of 12:0,14:0, and 16:0 and a lower concentration of 17:0. Only one strain of $Y$. pestis was analyzed. This strain differed from the other yersiniae by its lack of 13:0, its low concentration of 15:0, and its high concentration of $18: 1$.

The taxonomically distant group of $S$. typhi strains showed a fatty acid composition of pattern grossly similar to that of yersiniae (Table 2 ), but there were several marked differences in concentration. Thus, the $S$. typhi strains contained the additional compound 2-OH-14:0 and relatively large amounts of 14:0 and low amounts of $16: 1$ and $17: 0$ fatty acids.

\section{DISCUSSION}

Only a few strains of Yersinia have previously been examined for cellular fatty acids. Tornabene et al. $(9,23)$ found 16:1, 16:0, and 17:0-cyclo to be the principal acids of extractable lipids and
3-OH-14:0 to be the principal acid of the somatic lipopolysaccharides isolated from Y. pseudotuberculosis and Y. pestis; these four acids have also been found to be characteristic of other members of Enterobacteriaceae $(16,22)$. As shown in Table 2, these and some additional acids are characteristic of $Y$. enterocolitica. This species exhibits a fatty acid composition very similar to that of Y.pseudotuberculosis and of most enterobacterial groups (unpublished results).

The degree of intraspecies homogeneity within $Y$. enterocolitica is presently unclear. In terms of biochemical profiles, the species contains several distinct groups (biovars). DNADNA hybridization experiments have also revealed distinct groups. Brenner et al. (3) found biovars (= biotypes) 1,2 , and 3 of Knapp and Thal (15; Table 1) to belong to the same DNA relatedness group, whereas biovar 4 (atypical strains) formed two or three separate relatedness groups different from that of typical $Y$. enterocolitica strains. Moore and Brubaker (19), on the other hand, found high relatedness values among strains of $Y$, enterocolitica by use of the same technique, but on a more restricted number of strains. They stated that $Y$. enterocolitica constitutes a valid species, at least with respect to biovars 1 through 4 of Wauters (24; Table 1).

This biochemical or DNA-DNA hybridization-related heterogeneity within $Y$. enterocolitica was not reflected in the fatty acid composition. For example, only minute differences, if any, in fatty acid composition could be observed between the individual biovars and the indolepositive and -negative strains as well (Table 3). Thus, fatty acid composition is unlikely to be of value in resolving intraspecies heterogeneity.

The three Yersinia species studied exhibited fatty acid patterns which were only slightly dif- 


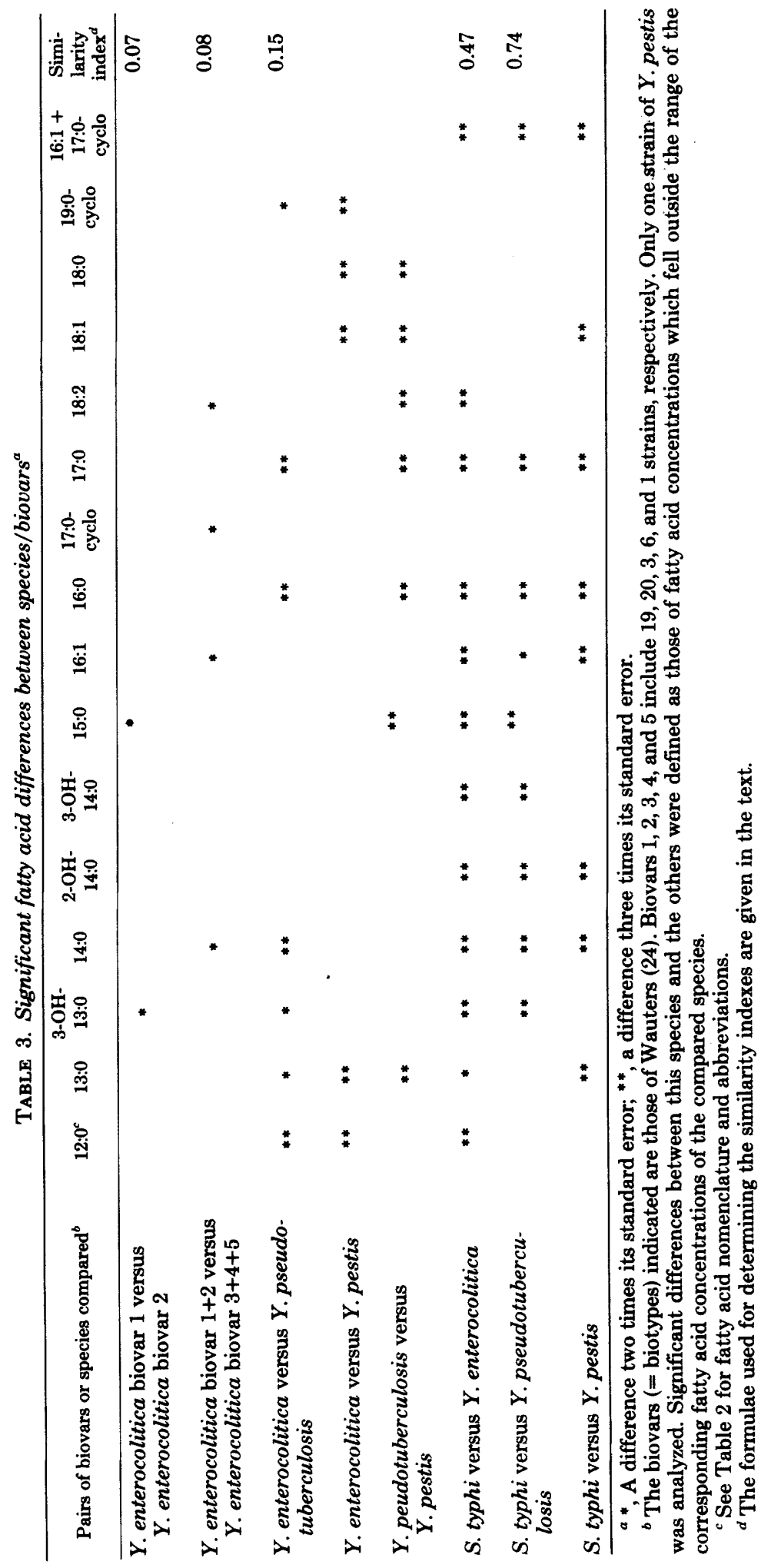


ferent from each other. The smallest deviations were observed between $Y$. enterocolitica and $Y$. pseudotuberculosis, whereas the single strain of $Y$. pestis was the most different from the other yersiniae. Since only one member of $Y$. pestis was analyzed, however, the taxonomic significance of this difference is questionable. Thus, the genus Yersinia appears to be homogeneous, and the fatty acid data on the yersiniae do not reflect the apparent taxonomic distance between $Y$. enterocolitica and $Y$. pseudotuberculosis as observed by DNA-DNA hybridization experiments $(3,19)$.

A reference group of five strains of Salmonella typhi was included in the study to determine the taxonomic position of Yersinia relative to another group of Enterobacteriaceae. Although the overall fatty acid pattern of $S$. typhi was found to be grossly comparable to that of Yersinia, several distinct differences were detected (Table 3). Of these, the presence of 2-OH-14:0 in $S$. typhi is interesting. This hydroxy fatty acid occurs together with the considerably more abundant isomer 3-OH-14:0 as a constituent of the endotoxic lipopolysaccharide and appears to be a stable taxonomic marker of the genera Salmonella, Klebsiella, and Serratia but appears to be lacking in Escherichia, Enterobacter, Shigella, and Proteus (5; unpublished data). These observations could indicate a closer relationship of Yersinia to the latter group of genera than to the former.

Compared with Pasteurella multocida, the fatty acid composition of Yersinia is markedly different. P. multocida lacks cyclopropane fatty acids and exhibits quite different concentrations of saturated and unsaturated straight-chain acids (unpublished results). Thus, the transfer of $Y$.pseudotuberculosis and $Y$. pestis from the genus Pasteurella to a genus of the family $E n$ terobacteriaceae (6) appears justified on the basis of fatty acid composition.

\section{REPRINT REQUESTS}

Address reprint requests to: Dr. Erik Jantzen, Statens Institutt for Folkehelse, Postuttak Oslo 1, Norway.

\section{LITERATURE CITED}

1. Abel, K., H. DeSmertzing, and J. I. Peterson. 1963. Classification of microorganisms by analysis of chemical composition. I. Feasibility of utilizing gas chromatography. J. Bacteriol. 85:1039-1044.

2. Barber, C., and E. Eylan. 1976. Immunochemical relations of Yersinia enterocolitica with Yersinia pestis and their connection with other Enterobacteriaceae. Microb. Lett. 3:25-29

3. Brenner, D. J., A. G. Steigerwalt, D. P. Falcäo, R. E. Weaver, and G. R. Fanning. 1976. Characterization of Yersinia enterocolitica and Yersinia pseudotuber- culosis by deoxyribonucleic acid hybridization and by chemical reactions. Int. J. Syst. Bacteriol. 26:180-194.

4. Brian, B. L., and E. W. Gardner. 1968. A simple procedure for detecting the presence of cyclopropane fatty acids in bacterial lipids. Appl. Microbiol. 16:549-552.

5. Bryn, K., and E. Rietschel. 1978, L-2-Hydroxytetradecanoic acid as a constitutent of Salmonella lipopolysaccharides (Lipid A). Eur. J. Biochem. 86:311-315.

6. Buchanan, R. E., and N.E. Gibbons (ed.). 1974. Bergey's manual of determinative bacteriology, 8th ed. The Williams and Wilkins Co., Baltimore.

7. Cronan, J. E., Jr. 1968. Phospholipid alterations during growth of Escherichia coli. J. Bacteriol. 95:2054-2061.

8. Drucker, D. B. 1977. Gas-liquid chromatographic chemotaxonomy, p. 51-125. In J. R. Norris and D. W. Ribbons (ed.), Methods in microbiology, vol. 9. Academic Press Inc., London.

9. Hartley, J. L., G. A. Adams, and T. G. Tornabene. 1974. Chemical and physical properties of lipopolysaccharide of Yersinia pestis. J. Bacteriol. 118:848-854.

10. Jantzen, E., K. Bryn, T. Bergan, and K. Bøvre. 1974 Gas chromatography of bacterial whole cell methanolysates. V. Fatty acid composition of neisseriae and moraxellae. Acta Pathol. Microbiol. Scand. Sect. B 82:767-779

11. Jantzen, E., K. Bryn, and K. Bøvre. 1974. Gas chromatography of bacterial whole cell methanolysates. IV. A procedure for fractionation and identification of fatty acids and monosaccharides of cellular structures. Acta Pathol. Microbiol. Scand. Sect. B 82:753-766.

12. Jantzen, E., K. Bryn, N. Hagen, T. Bergan, and $\mathbf{K}$. Bøvre. 1978. Fatty acids and monosaccharides of Neis. seriaceae in relation to established taxonomy. NIPH Ann. (Oslo) 1:59-71.

13. Johnson, R., R. R. Colwell, R. Sakazaki, and K. Tamura. 1975. Numerical taxonomy study of the $E n$. terobacteriaceae. Int. J. Syst. Bacteriol. 25:12-37.

14. Knapp, W., and E. Thal. 1973. Differentiation of Yersinia enterocolitica by biochemical reactions. Contrib. Microbiol. Immunol. 2:10-16.

15. Lassen, J. 1972. Yersinia enterocolitica in drinking water. Scand. J. Infect. Dis. 4:125-127.

16. Lechevalier, M. P. 1977 . Lipids in bacterial taxonomya taxonomists view. CRC Crit. Rev. Microbiol. 5:109210.

17. Le Minor, C., A.-M. Chalon, and M. Véron. 1972. Recherches sur la présence de l'antigene commun des "Enterobacteriaceae" (antigene Kunin) chez les "Yersinia," "Levinea," "Aeromonas" et "Vibrio." Ann. Inst. Pasteur (Paris) 123:761-774.

18. Maeland, J. A., and A. Digranes. 1975. Common enterobacterial antigen in Yersinia enterocolitica. Acta Pathol. Microbiol. Scand. Sect. B 83:382-386.

19. Moore, R. L., and R. R. Brubaker. 1975. Hybridization of deoxyribonucleotide sequences of Yersinia enterocolitica and other selected members of Enterobacteriaceae. Int. J. Syst. Bacteriol. 25:336-339.

20. Morris, L. J., H. Hayes, and R.T. Holman. 1961. Naturally-occurring epoxy acids. III. Methods for their isolation. J. Am. Oil Chem. Soc. 38:316-321.

21. Nilehn, B. 1969. Studies on Yersinia enterocolitica. Acta Pathol. Microbiol. Scand. Suppl. 206:1-48.

22. Shaw, N. 1974. Lipid composition as a guide to the classification of bacteria. Adv. Appl. Microbiol. 17:63108.

23. Tornabene, T. G. 1973. Lipid composition of selected strains of Yersinia pestis and Yersinia pseudotuberculosis. Biochim. Biophys. Acta 306:173-185.

24. Wauters, G. 1973. Correlation between ecology, biochemical behavior and antigenic properties of Yersinia enterocolitica. Contrib. Microbiol. Immunol. 2:38-41. 